\title{
Creatividad, Pensamiento y ARTIVISMo feminista en ChILE ¡Ahora es cuando!
}

\author{
Creativity, Thought and Feminist Artivism in Chile: Now is when!
}

\author{
MARLA Freire SMith
}

Universidad Autónoma de Chile, Chile

\begin{tabular}{l} 
KEY WORDS \\
\hline Creativity \\
Feminism \\
Artivism \\
Performativity \\
History of Art
\end{tabular}

PALABRAS CLAVE

Creatividad

Feminismos

Artivismo

Performatividad

Historia del arte

\begin{abstract}
The actions made by feminist colectives and groups in Chile has reconfigured the ways of conceiving action art and generates collective catharsis. "Acuerpar" the public space, renaming Metro de Santiago stations and streets to make women visible, show historical omission but also epistemic violence. Based on feminist epistemologies, this article analizes how creativity and feminisms through performativity expressed by different groups and artists (Yeguada Latinoamericana y LasTesis, among others), power structures can be destabilized and deconstruct the history(s).
\end{abstract}

\section{RESUMEN}

Las distintas acciones realizadas por colectivos y grupos feministas en Chile reconfiguran las formas de concebir el arte de acción y generan catarsis colectivas. "Acuerpar" el espacio público, renombrar las estaciones de Metro de Santiago y calles para visibilizar mujeres, evidencian la omisión histórica pero también, la violencia epistémica. A partir de las epistemologías feministas este artículo analiza cómo creatividad y feminismos, a través de la performatividad a cargo de distintos grupos y artistas (Yeguada Latinoamericana y LasTesis, entre otras) podrían desestabilizar estructuras de poder y deconstruir la(s) historia(s). 


\section{Introducción}

$\mathrm{E}$ n el año 2017 las calles de Chile por primera vez se hacen eco de las demandas contra los abusos sexuales ocurridos en espacios universitarios, a raíz de las denuncias y acciones realizadas por las estudiantes de las ciudades de Valdivia y Temuco. Las universitarias, entre las variadas estrategias de visibilización que utilizan, realizan acuartelamientos en sus centros de estudio, impidiendo el paso de académicos y funcionarios, acusando el encubrimiento y falta de medidas en casos de abuso sexual (Publimetro, 2019; El Dínamo, 2018). Les siguen en este tipo de denuncias, las universitarias de las ciudades de Santiago y Valparaíso, hasta que continúan se sumándose las demás instituciones a lo largo del país, denunciando la naturalización del abuso sexual en espacios educativos. Con este escenario, en mayo de 2018 ocurre lo que hoy reconocemos como Mayo Feminista, pues tal como señala la antropóloga Francisca Fernández:

Si hoy podemos hablar de un mayo feminista es porque anteriormente se han generado diversas movilizaciones de mujeres $y$ organizaciones, que han sostenido y son referentes del proceso actual. Pero también es importante reconocer que estamos ante un escenario de movilización feminista de gran envergadura, en que miles y miles de mujeres han salido a las calles (Fernández, 2019).

Sin duda el Mayo Feminista marca un punto de inflexión a la hora de manifestarse en Chile. A partir de ese momento, el aumento de participantes en las marchas va en crecimiento constante y los motivos por los que manifestarse, también. Para dejar claro este punto, desde el año 2017 el tenor ha sido el aumento en el número de asistentes en cada marcha, concentración y protesta, sumado a la necesidad de acuerpar las calles (Qué Pasa, 2019). A modo de ejemplo, decir que sólo en una de las jornadas del Mayo feminista del año 2018 en Santiago de Chile, asistieron más de ciento cincuenta mil personas (Qué Pasa, 2019) y que en las actividades del 8 de Marzo del año 2019, asisten cerca de cuatrocientos mil asistentes en Santiago y ochocientos mil a nivel nacional (El Desconcierto, 2019). Todo esto, a modo de precedente de lo ocurrido en una de las jornadas del reciente estallido social en el país, concretamente el viernes 25 de octubre de 2019, cuando cerca de un millón doscientas mil personas acudió a Plaza Italia y sus inmediaciones, en lo que se conoció como "La marcha más grande de Chile" donde además de visibilizar las demandas sociales que cruzan transversalmente a la sociedad, se hacía para demandar acerca de las inequidades a causa de sexo y género (Tele13radio, 2019). Hay que señalar que, debido al éxito de la convocatoria, la acción fue replicada en distintas ciudades del país: cincuenta mil personas en Concepción (El Desconcierto, 2019) y otros miles en Valparaíso y Viña del Mar (La Tercera, 2019).

En clave feminista, es posible situar estos dos momentos como puntos de inflexión respecto de manifestaciones masivas para denunciar vulneraciones sistemáticas. En este sentido, las contestaciones ciudadanas a la violencia hacia las mujeres no se hacen esperar y el 8 de marzo del 2019, a través de una de las marchas más multitudinarias que se han visto desde recuperada la democracia (El Desconcierto, 2019) y diversas acciones convocadas en su mayoría por la Coordinadora $8 \mathrm{M}$, se evidencia que la ciudadanía exige cambios estructurales. Esta fecha, el 8 de marzo de 2019, es elegida por la Coordinadora 8M para entablar reflexiones acerca de las mujeres omitidas en la historia oficial. Para ello, realizan una serie de acciones performáticas destinadas a visibilizar esto a través de intervenciones gráficas, que consistían en poner pegatinas a gran escala con los nombres de estas mujeres sobre los carteles con los nombres originales de las estaciones de Metro de Santiago, así como en algunas calles de la ciudad. Todos estos momentos han valido para reposicionar las demandas sociales, pero también han subrayado aquellas que, desde los feminismos, se vienen enunciando desde hace décadas. Ejemplo de estas demandas, han sido recogidas en el "I Encuentro Plurinacional de Mujeres que Luchan" realizado en el año 2018 (AAVV, 2019), que buscaba evidenciar las profundas desigualdades existentes en el país y la necesidad de diseñar, en conjunto con la ciudadanía, un nuevo pacto social reflejado en una nueva Constitución Política de la República de Chile.

Este tipo de acciones claramente constituyen una antesala a la hora de aproximarnos 
teóricamente al trabajo desarrollado por Yeguada Latinoamericana y el colectivo LasTesis, pues suponen una amplificación del uso del espacio público, al mismo tiempo que trascienden las normativas de ocupación y uso con fines políticos, desestructurando las lógicas de normatividad y poder, como se revisará más adelante. Dichas acciones son realizadas en un contexto enmarcado por el estallido social comenzado en octubre de 2019. Y entendiéndolo así, no es de extrañar que las reflexiones sociales que proponen se centren en visibilizar los abusos y en "acuerpar" las calles como estrategia política, siguiendo el concepto propuesto por Lorena Cabnal que define como: "la acción personal y colectiva de nuestros cuerpos indignados ante las injusticias que viven otros cuerpos que se auto convocan para proveerse de energía política para resistir y actuar contra las múltiples opresiones patriarcales, colonialistas, racista y capitalistas" (Cabnal, 2015). Es entonces que, con estas experiencias de acuerpamiento en el espacio público, se convocan acciones masivas de evasión del Metro de Santiago y jornadas de visibilización en el espacio público, de acciones junto a Yeguada Latinoamericana y al colectivo LasTesis. En este punto, creo importante mencionar que tanto en las acciones de descontento social, así como en las activaciones del movimiento feminista o en los trabajos de estos grupos y colectivos, no hubo lideresas, cabecillas o una organización que congregara de manera constante, sino que se trató de puestas en escena acuerpando las calles a través de la complicidad colectiva y la estrategia de convocatoria a través de las redes sociales, como se revisará a lo largo de este artículo.

Cabe señalar que en este texto me ciño al concepto de artivismo, entendiéndolo como un neologismo que une las palabras activismo y arte, para referirme a un arte cargado de contenido político (Aladro-Vico, E., Jivkova-Semova, D., Bailey, 0., 2018) y basado en la recuperación de la acción artística con fines de inmediata intervención social (Expósito, 2013). Al proponer el artivismo feminista como centro, vale recordar que la calle y el espacio público, en tanto espacio de poder, han sido históricamente limitados para las mujeres, por ello la importancia de analizar el acuerpamiento de las calles como estrategia que hace tambalear las estructuras de poder, ya sea a cargo de distintas agrupaciones o bien de la mano de artistas, pues, tal como señala Ana María Devaud: "el feminismo nunca ha dejado de actuar (...) y su influencia en el reciente estallido social es notable" (Devaud, 2020:5).

\section{Metodología}

Este estudio plantea una metodología de trabajo basada en dos direcciones: por un lado se encuentra la revisión de fuentes bibliográficas primarias y secundarias, así como análisis documental (material gráfico), además de experiencias de trabajo propias desde el artivismo feminista e incluso conversaciones con artivistas feministas. De esta forma, se realiza consulta de archivos, bibliotecas, hemerotecas y se incorporan reflexiones surgidas a raíz de conversaciones con artistas respecto de su trabajo. La segunda dirección se da a través del método semiótico (Agudelo, 2014; Eco, 2007; Klinkenberg, 2006; Peirce, 1998) para focalizarnos en la interpretación de parte de la producción artística realizada por el grupo Yeguada Latinoamericana y el colectivo LasTesis. Desde el inicio de este estudio se decidió que la metodología debía contemplar fuentes variadas y multidisciplinares, ya que el punto de partida está en la epistemología feminista (Alcoff y Potter, 1993; Harding, 1986, 1991; Zalaquett, 2012) y ello significa necesariamente abrir la reflexión y discusión desde distintas aristas. Por ello, no se pretende realizar una recolección de hechos ni acontecimientos $\mathrm{y}$ mucho menos realizar un trabajo que contemple solamente el punto de vista histórico: aquí es donde entra en valor la interpretación de las obras realizadas tanto por LasTesis como por Yeguada Latinoamericana. Por ello, en este análisis, el enfoque metodológico es dado, en primer término, por la teoría crítica (Flórez, 2015; Maffia, 2004; Tabares, 2019; Trebisacce, 2016) para poder observar importantes fisuras en la historiografía del arte chileno y plantear lecturas que complementan los relatos existentes. El segundo eje de trabajo en esta línea es la utilización del principio de deconstrucción que permite observar los cuestionamientos que LasTesis y Yeguada Latinoamericana proponen, precisamente, a raíz de lecturas estéticas a sus obras. 
Desde estos ejes mencionados, el objetivo general es: analizar, interpretar y establecer vínculos entre las obras realizadas por diversos grupos y colectivos feministas en relación a su contexto socio-político. Los objetivos específicos, en tanto, son: describir el contexto sociopolítico y su relación con el artivismo feminista; realizar lecturas teóricas a las acciones realizadas por grupos feministas (Yeguada Latinoamericana y colectivo LasTesis) y proponer que desde la performatividad es posible generar disenso para desestabilizar las estructuras de poder.

De acuerdo con estos objetivos, surgen las siguientes preguntas de investigación: ¿existe alguna relación entre el trabajo realizado por diversos colectivos o grupos feministas y las acciones realizadas por LasTesis y Yeguada Latinoamericana en cuanto a la desestabilización del poder político?, ¿pudo influir Yeguada Latinoamericana y LasTesis en la forma de protestar que se estaba llevando adelante? Ante estas interrogantes, la hipótesis preliminar es que los colectivos y las agrupaciones feministas, así como Yeguada Latinoamericana y LasTesis, se nutren de las acciones estéticas desarrolladas anteriormente en el espacio público, documentadas ampliamente en la historia del arte chileno y los movimientos sociales (Alcázar, et al., 2005; Mellado, Richard, 1983; Morales, 1998; Richard, 1993, 1994, 1998, 2000, 2001, 2005, 2007, 2008; Sánchez, 2005; Valdés, 1996, 2006, entre otros).

\section{A modo de contexto: la necesidad de escribir una historia propia}

Para este análisis es importante mencionar en primer término, la acción realizada el 8 de marzo del 2019 convocada por la Brigada de Arte y Propaganda de la Coordinadora Feminista 8M, reúne cerca de doscientas mujeres, para renombrar 46 estaciones del Metro de Santiago (de las 136 existentes) con adhesivos de nombres de distintas mujeres a escala $1: 1$, proponen un nuevo plano del metro: un plano feminista en la ciudad. La razón de esta intervención es quebrar la historia patriarcal a través del nombrar y reconocer a mujeres importantes, así como a activistas de la disidencia sexual que contribuyen a marcar una posible genealogía de las luchas actuales. A este respecto, Alondra Castillo, una de las voceras de la coordinadora $8 \mathrm{M}$, señala: "Mostramos nombres de mujeres que forman parte de la memoria histórica feminista y por lo mismo de nuestra vida actual, pero que no son parte de la ciudad que habitamos. (...) reivindicamos una memoria histórica feminista". (Publimetro, 2019). Es importante mencionar que esta acción performática evidencia que las estructuras de poder y control pueden ser desestabilizadas a partir de acciones concretas en la ciudad. En este sentido, el reclamo no pasa solamente por el discurso, a través de la palabra, sino que se instala en la ciudad y contribuye al diálogo entre la propia ciudadanía, posicionando políticamente a los sujetos.

A lo anterior, hay que añadir que las denuncias de estas marchas fueron posicionadas y recogidas previamente durante el año anterior y han vuelto a salir a la luz en la revolución actual que estalla en octubre de 2019. Estas demandas, recogidas en el "I Encuentro Plurinacional de Mujeres que Luchan" (2018) ahora están presentes en los muros de la ciudad a través de graffitis, murales y collages, convirtiéndose en un museo abierto (de la historia no oficial) quebrando la historia vertical y androcéntrica impuesta. En estos muros puede verse una historia donde la lógica de la derrota es evidente. De esta forma, a través del grafiti, murales y pegatinas a gran escala, se han subvertido los códigos de dominación, transgrediendo simbólica y culturalmente las calles, escribiendo historias propias (Instagram: $@$ @useodeladignidad). A este respecto, cabe señalar brevemente que hace unos meses atrás el actual Gobierno de Chile decidió que las asignaturas de Historia y Educación Física ya no serían parte del currículum escolar para estudiantes en sus dos últimos años de educación. Por lo que la acción de escribir sobre los muros las demandas, pero también las denuncias acerca de los abusos cometidos estos últimos treinta años por parte del Estado, así como las constantes vulneraciones a los derechos humanos ocurridas estos meses, son una forma de construir memoria a través de la imagen de la textualidad, que se preservará a través de fotografías y/o recursos audiovisuales por la ciudadanía. Por supuesto, algunas 
escrituras tratan también acerca de consignas que apelan a la deconstrucción y la inclusión de los saberes sometidos (Foucault, 1979).

Curiosamente, es también la calle donde tiene lugar otro tipo de intervención a la historia oficial en la revuelta actual que vive Chile, a través del derrocamiento de distintas esculturas de corte militar. Diversas esculturas de conquistadores o personajes asociados a las Fuerzas Armadas han sido decapitadas o abiertamente destruidas en un derrocamiento de la historia colonial, donde es evidente el gesto feminista detrás, en el sentido de buscar deconstruir las verdades instaladas como inamovibles y proponer, al mismo tiempo, una revisión de las historias impuestas. Es de considerar que este tipo de monumentos refuerza una memoria colonial de subyugación desde las calles y plazas más importantes y transitadas del país, impidiendo habitar la memoria desde otros frentes y desde otras perspectivas. Aquí resulta importante recordar que el primer derribo ocurre diez días después del estallido, el 29 de octubre de 2019 en la ciudad de Temuco, con la figura del militar y conquistador Pedro de Valdivia y del aviador chileno Dagoberto Godoy. La cabeza de este último es dejada en las manos de la escultura del Toqui Caupolicán. Días después, comunidades lafkenche derriban en Cañete otra escultura de Pedro de Valdivia y una de García Hurtado de Mendoza (fundador de la ciudad). Días más tarde, nuevamente una escultura de Pedro de Valdivia es intervenida (Plaza de Armas de Santiago), esta vez con atuendos propios de los pueblos originarios, mientras los convocantes llaman a realizar una Asamblea Constituyente Plurinacional. A estas acciones, se suma otra en la ciudad de La Serena a manos de diversas organizaciones que buscan renombrar la avenida Francisco de Aguirre como Avenida Diaguita. (Página 7, 2019). Todas estas acciones, en palabras de Antonia Huentecura, vocera de la Coordinación de Naciones Originarias de la Región Metropolitana, se fundamentan en lo siguiente: “(...) este país nos ha invisibilizado y nos ha llenado de héroes y estatuas que no tienen que ver con las primeras naciones de este territorio" (Interferencia, 2019). Siguiendo con la afrenta a las historias coloniales, el viernes 1 de noviembre de 2019, en la ciudad de Arica, se derriba una escultura de Cristóbal Colón, mientras que en la Plaza de La Serena, la escultura de Francisco de
Aguirre. En su lugar, se deja la de Milanka, una mujer diaguita creada por la agrupación Casa La Nuez. A este respecto, Carolina Herrera Rojas, meica diaguita (sanadora) señala: "La imagen de la Milanka tiene una simbología muy profunda en lo que tiene que ver con nuestra cultura matriarcal. La mujer amamantando tiene que ver con la fuente de vida, representa parte de la cosmovisión diaguita, con el orden del equilibrio, el cuidado de las aguas, de los ríos y las semillas", explica (Interferencia, 2019).

Al releer estas deconstrucciones de la historia oficial en clave feminista (tanto en el diseño del Plano Feminista como en los derrocamientos de monumentos), es posible entender el sentido de resignificar la memoria y girar la mirada hacia otras historias, incluyendo la de nuestros pueblos originarios y la de mujeres que han contribuido a la conformación de nuestra nación. A este respecto, es importante rescatar las palabras del historiador mapuche Herson Huinca-Piutrin, que plantea que estos actos no deben leerse simplemente como hechos vandálicos, sino que "vienen a hacer ruido en la memoria histórica (...) dichos monumentos encarnan el genocidio de los pueblos indígenas, como también la validación del patriarcado en la memoria histórica oficial" (Interferencia, 2019). El historiador reconoce que la historia de Chile, tal cual la conocemos, es una historia patriarcal enhebrada al hilo del colonialismo que omite historias propias de nuestros pueblos en AbyaYala ${ }^{1}$, a lo que habría que añadir, que además omite historias y nombres de mujeres que han contribuido desde diversas áreas a la conformación de la nación y al avance del conocimiento, un hecho subsanado simbólicamente el pasado 8 de Marzo de 2019.

\section{Acerca de las obras: el cuerpo en rebeldía}

La denuncia a la violencia estructural por parte del Estado de Chile se ha tomado las calles del país y ha significado un resurgir de las protestas para hacer evidente la necesidad de acuerpar el espacio público. Desde esta lectura, es posible dar cuenta que el artivismo feminista se vuelve intenso y

${ }^{1}$ Nombre del continente americano en lengua Kuna (actual Panamá y parte de Colombia). N. de A. 
necesario. Históricamente, el artivismo en Chile se ha manifestado en momentos de convulsión política y de violencia hacia el cuerpo. Ejemplo de ello lo vemos en las obras de artistas como Diamela Eltit, el grupo CADA, Raúl Zurita, Paulina Humeres, Las Yeguas del Apocalipsis, Pedro Lemebel, Colectiva Piano Ramón Carnicer o Luger de Luxe, entre otros grupos y artistas de las décadas setenta, ochenta y noventa (Freire, 2015), pero también en artistas activas como Janet Toro, SenoritaUgarte, Gabriela Rivera, Eli Neira o Marla Freire (quien escribe), así como en Cheril Linett (Yeguada Latinoamericana), Sibila Sotomayor, Dafne Valdés, Paula Cometa y Lea Cáceres (Colectivo LasTesis), en quienes me centraré en esta segunda parte del artículo. Todas artivistas feministas, con todo lo que ello implica: desde censura hasta omisión por parte de cierto establishment que pretende homogeneizar los discursos y las prácticas artísticas, subyugándolas, al mismo tiempo que evidencia las diferentes estrategias que estas artistas sortean a la hora de inscribir y visibilizar su trabajo.

\section{(Re) lectura a Yeguada Latinoamericana}

En esta parte me centraré en el trabajo de la Yeguada Latinoamericana, en las acciones "Banda de guerra" (2018) y "Estado de rebeldía" (2019). Antes de hacer una lectura acerca de su trabajo, es pertinente señalar el origen del nombre del grupo, pues desde allí se comprende mejor su práctica artística. En palabras de su directora, la artista Cheril Linett:

Nos autodenominamos yeguada y recordamos el proceso de colonización que introdujo animales no originarixs de estos territorios con el objetivo de instrumentalizarles, disciplinarles, someter su movimiento, su existencia y utilizarles como tecnología militar. En su segunda visita, Colón trajo una yeguada de 7 hembras con el propósito de esclavizarlas para reproducción y carga. Hacemos ahí un cruce con nuestras propias cuerpas fragmentadas, cosificadas, etiquetadas para el consumo. Nuestros órganos son nombrados por la tecnología política del cuerpo como "órganos reproductores", mutilando el deseo, el sexo, invisibilizando y negando la utilización de éstos para el placer, castigando la transgresión. (Linett, C., Concha, J., Remmele, L., 2018).
Es preciso aclarar que se trata de un grupo de artistas dirigidas por Cheril Linett y que en cada acción que realizan se vuelven un cuerpo múltiple, y, siguiendo a Zigmunt Bauman (2004), también líquido, adaptándose al espacio donde realizan sus intervenciones. Las acciones de Yeguada Latinoamericana proponen una revisión constante de conceptos como objeto/sujeto, así como de la circulación de ellos. De esta forma, plantean reflexiones que van más allá del género y de reivindicaciones en este aspecto, ya que proponen hacerlo acerca del flujo que implica la construcción constante de la multiplicidad del cuerpo, y, por ello, de los relatos y de cómo estos cambian según lo hace el contexto o el contenedor de su trabajo.

Desde la construcción del cuerpo a través del vestuario, y a partir de la escenografía corporal que busca abrir los binarismos de especie (animal-humano) hasta los desplazamientos que surgen con sus acciones, Yeguada Latinoamericana nos habla también de flujos y multiplicidad, de indeterminaciones respecto de cuerpo y especie, al tiempo que confrontan al poder normativo. En este sentido, Sayak Valencia señala que Yeguada evidencia: “(...) la ruptura del antropocentrismo a través de lo transespecie y la corpo-decolonialidad (...) cuerpos excedentes-bestiales que en su marginación representan las máquinas de trabajo $\mathrm{y}$ reproducción históricamente feminizadas y/o racializadas que son el soporte material" (Valencia, 2018). Aquí el punto de tensión importante viene dado por María Lugones que señala que raza $y$ género son ficticias, señalándolas como: "ficciones poderosas" (Lugones, 2008: 94).

En Yeguada Latinoamericana, se hace presente además la idea de un "cuerpo líquido" por tratarse tránsitos constantes, reforzados a través de su nombre y el lenguaje, que visibiliza y hace circular lo indefinido, lo trans-especie. De esta forma, lo monstruoso que pueda derivarse, no es otra cosa que una particular belleza que surge desde la indeterminación de especies. Acaso por ello, me atrevo a proponer que sobrepasa la lógica habitual de análisis, ya que en sí es movimiento y multiplicidad constante. Un cuerpo líquido que se adapta al contenedor desde el cual se analiza y desde donde se le 
observe (las calles, memoriales de Carabineros, las afueras del Palacio La Moneda, etc.). La circulación constante ocurre desde la construcción de su cuerpo y acciones, hasta la circulación de ellas a través del formato de archivo (fotográficos y/o de vídeo) y su circulación por medio de redes sociales. Desde esta lectura, sus cuerpos devienen "un otro" constantemente, como un proceso de mutación exagerada que termina por imponerse, y por ello, descolonizando cada cierto tiempo en la misma medida que se le intenta definir. Siguiendo a Bauman (2004), podría decirse que se trata de un diseño líquido inter-especie. El presentarse de esta forma, convierte sus cuerpos en territorios políticos, donde las marcas que lo constituyen como tal generan cuestionamientos que se hacen visibles en un nuevo cuerpo inter/trans- especie.

La desterritorialización (Deleuze y Guattari, 1997), en el caso de las intervenciones de Yeguada Latinoamericana actúa entonces como un fuera de cuerpo, un depositario de otros que no sabemos qué son. En este caso, el debate se plantea además respecto de las categorías, al tratarse de un cuerpo que cambia de estado, que une dos especies y que señala nuevas posibilidades de reconfiguración. La de individuo/sujeto, en este caso, cambia de forma y se adapta a aquello que lo contiene constantemente. Primero lo hace el cuerpo, luego el personaje que se crea (mezcla interracial) y finalmente a todo lo que le contenga (vestidos, túnica, calles, espacios, etc.). Esta tensión constante es la que constituye su multiplicidad contra la normatividad y la homogeneización de los cuerpos, las especies, y, por supuesto, del discurso. De esta forma, hay deconstrucción del cuerpo para convertirse en cuerpos múltiples y desterritorializados, hasta transformarse en cuerpos líquidos. Esta estrategia, claramente política, ayuda a escapar del disciplinamiento corporal, de especies y de la(s) historia(s), en tanto del cuerpo (los cuerpos) como reflejos de ella. Desde esta lectura, estos cuerpos escenografiados y líquidos al mismo tiempo, transgreden las marcas del cuerpo como territorio en una circulación que cataliza el proceso de descolonización, al evidenciar la relación cuerpo/especie colonizadocuerpo/especie colonizador, a propósito de la imagen que se crea con las colas de caballo/yegua. Es decir, los cuerpos anteriormente colonizados, ya sea por el discurso o la forma de análisis, en esta nueva condición no serían ya territorios conquistados, pues esa condición se abandonaría al tratarse de fusiones de especies, emancipando de esta forma, los cuerpos.

Yeguada Latinoamericana vuelve su cuerpo un territorio múltiple, cambia el foco, posibilita el surgimiento de "otras historias" (microhistorias) que cobran sentido desde esta mirada. En ese sentido, y tomando el concepto de "despatriarcalizar" acuñado por María Galindo (integrante del colectivo boliviano Mujeres Creando), Yeguada Latinoamericana contribuye a despatriarcalizar las historias y el disciplinamiento de los cuerpos. De esta forma, las historias múltiples se hacen presentes a través de un cuerpo también múltiple, desde las especies, los sexos y los géneros, para subrayar lo negado por la historia oficial: la otredad en su amplio sentido de la palabra.

\section{(Re) lectura a LasTesis}

En cuanto al trabajo realizado por el colectivo LasTesis, compuesto por Sibila Sotomayor y Dafne Valdés (artes escénicas), Paula Cometa (diseño e historia) y Lea Cáceres (vestuario), vemos que buscan divulgar teorías feministas y ponerlas en escena. En la intervención "Un violador en el camino" (2019), a estas alturas ampliamente conocida, vemos que ha sido creada a partir de la lectura de autoras como Silvia Federici y Rita Segato, evidenciando la importancia de acorralar los discursos patriarcales desde todos los frentes, como ocurre en este caso: desde la calle, las artes, y, por supuesto, el trabajo colectivo apoyado en las redes sociales. Respecto de esta intervención, es posible identificarla como una pieza de arte de performance, considerando que uno de los objetivos de este tipo de arte es, precisamente, unir arte y vida. Pero también puede ser entendida como artivismo, subrayando $y$ encarnando lo popularizado por Carol Hanisch, que termina siendo emblema de los feminismos de los años setenta: "lo personal es político" (1969). De esta forma, LasTesis investigan y divulgan conocimiento feminista a partir del 
estudio que hacen de las obras de Segato y Federici, para evidenciar que la violación no se trata solamente de un asunto sexual, sino mucho más grande: se trata de control y poder (Segato, 2016). En su intervención, ahondan en ello y desmitifican además que se trate únicamente de sometimiento de carácter sexual, aunque explicitan que se trata de uno con carácter corpóreo. Por eso la referencia directa al Estado: porque hay un intento de usurpación de la integridad de las personas (y de su dignidad, cuando nos referimos, por ejemplo, a las pensiones, temas de salud, etc.). Y porque esto es más fuerte todavía al referirnos a las mujeres. De esta forma, LasTesis, evidencian que el neoliberalismo se sustenta en una violencia extrema de sometimiento, de dominación patriarcal y control sobre el cuerpo.

A lo anterior hay que añadir que la intervención de LasTesis, particularmente en Chile, cambia el interés sobre el sujeto político que se manifiesta en medio del estallido social, así como la manera de hacerlo (en su mayoría se trataba de varones, llegando a hablarse incluso de "héroes"). De esta forma, redirige la atención sobre las mujeres y las problemáticas enunciadas, con especial atención a la violencia político sexual, cambiando además el foco mediático puesto en la violencia a la hora de manifestarse para situarlo en la violencia político sexual.

A lo señalado, es posible añadir que LasTesis proponen además disolución de la autoría personal (es más importante realizar la acción que señalar autorías) proponiendo además un acuerpamiento en las calles, al mismo tiempo que se divulgan contenidos feministas, tensionando, de esta forma, varios frentes. Desde redes sociales invitan a ser parte de la acción, a través de una convocatoria abierta, llamando a realizarlas en el espacio público para visibilizar los abusos hacia las mujeres, con énfasis en la violencia política sexual, evidenciada en la letra de la canción. De esta forma, su acción es masificada por las redes, haciendo eco de lo que Nuria Varela denomina feminismo 4.0 (Varela, 2019) es decir, un feminismo definido por la tecnología, que permite construir de manera online, fuerte, popular y reactiva. Pero, detrás de estas acciones realizadas por ellas (y sus réplicas mundiales) hay otro fenómeno que puede también leerse (y que, al menos en este caso, no enfría la acción): la observación de las intervenciones mundiales es permeada por las pantallas, por los archivos, lo que nos convierte en espectadores de nuestra propia realidad. Entonces, tal como señala José María Lasalle, hablamos de un momento en que las "interfaces digitales se convierten en las nuevas vías de acceso a una identidad extirpada de lo corpóreo" (Lasalle, 2019:49). Al referirnos a esta intervención, la idea de extirpación de lo corpóreo se hace presente al mismo tiempo que las calles se desbordan de cuerpos de mujeres que se sitúan al centro del espacio público (y virtual).

\section{A modo de conclusión}

En las acciones comentadas en este artículo, la apropiación del espacio público y el trabajo colectivo han sido centrales a la hora de buscar desestabilizar el poder político. Ello por supuesto ha encontrado un potente resonante en la utilización de las redes sociales, que han jugado un rol fundamental a la hora de convocar y viralizar las acciones. Ello también ha supuesto que facilitara las réplicas de muchas de ellas (concretamente de LasTesis) evidenciando demandas sociales referidas a la inequidad, que se espera sean canalizadas en la escritura de una nueva Constitución Política de Chile. Respecto del resonante que han significado las redes sociales en este proceso, es importante mencioanr que la distancia (o cercanía) que causa la hipermediatización del cuerpo, produce además una cualidad inmersiva, tal como señala Lasalle (2019) pues, al estar hiperconectados se evidencia este fenómeno. Esto ocurre especialmente en el caso de LasTesis, sin importar cuándo haya ocurrido la acción (ni dónde). Y es así producto de que la violencia hacia las mujeres es tal, por el sólo hecho de serlo: evidencia la magnitud de un problema que es mundial. Sin embargo, estas reflexiones respecto de las redes sociales también se ven en la demandas de distintos colectivos y partidos políticos a la hora de realizar sus acciones y esperar que estas sean registradas para tenerlas en cuenta al momento de levantar los puntos a ser considerados en una nueva Constitución. Por contraparte, y centrándonos en cómo han sido organizadas las intervenciones de LasTesis (y sus distintas versiones) sabemos que han sido 
coordinadas a través de redes sociales, vía mensajes de Whatsapp o invitaciones a participar a través de Instagram. Se trata por tanto de herramientas que dan cuenta de lo líquido y dúctil del llamado, pero también de la urgencia en encontrar alguna respuesta 0 solución, $y$, al mismo tiempo, de la necesidad de poner el cuerpo en la calle y hacerlo visible. Esto, también se da en el caso de Yeguada Latinoamericana, pues sus denuncias apuntan precisamente a estructuras de poder que no han sido reformuladas, $y$, para que su mensaje llegue, requieren de la tecnología para hacer visibles sus acciones, que, de otra forma, tendrían un público y efecto reducido. En ambos ejemplos de artivismos feministas, y considerando además las acciones realizadas en el espacio público a partir del Mayo feminista (2018) y por la Coordinadora $8 \mathrm{M}$, se evidencia la necesidad de denunciar las formas en que el Estado se hace parte de los abusos hacia la sociedad, concretamente hacia las mujeres. Estas evidencias de abusos se vuelven visibles a través de las acciones realizadas en el espacio público, las que son replicadas por medio de redes sociales hasta volverse masivas, $y$, de cierta forma, visibles al punto que pueden interpelar al poder. Ahí es donde está una de las claves del alcance de su mensaje y la capacidad de hacer tambalear las estructuras de poder normativo del Estado que sostienen dichos abusos e inequidades. A ello se suma que las estrategias utilizadas, apoyadas en el uso de la creatividad en el espacio público, han sido seguidas y replicadas de distintas formas a través del registro y su posterior viralización por medio de las redes sociales, por ello sería coherente afirmar que pueden verse influencias del artivismo feminista en las formas de protestar por distintos grupos (y por la ciudadanía en general) una afirmación constatada recientemente el pasado 8 de marzo de 2020, en la conmemoración del día de la mujer trabajadora, en el cual se realizaron actividades en las calles que tenían como móvil el feminismo y un cuidado trabajo de visualidad, amplificado a través de las redes sociales.

A lo anterior se añade que, además de evidenciar las estrategias feministas, el uso de la tecnología nos recuerda una de las afirmaciones de Alejandra Castillo (2018) respecto de la revuelta feminista, cuando nos dice que es capaz de convocar múltiples prácticas y formas de resistencia, al ser su orden la oblicuidad. Esto es evidente en los artivismos feministas analizados en este artículo, tanto por parte de las agrupaciones políticas como por Yeguada Latinoamericana y LasTesis, pues sus estrategias de acción trascienden lo esperado dentro de las artes visuales, pero también desde los feminismos, al trabajar de forma interdisciplinaria $(0, a)$ estas alturas, indisciplinadamente) pero además, desde distintos frentes, siendo propuestas líquidas, como diría Bauman, al tiempo que se apoyan en las redes sociales a modo de estrategia feminista, tal como plantea Nuria Varela (2019). De esta forma, no solo desestabilizan el poder normativo, sino que, en ocasiones, logran además cambiar el sujeto político de la revuelta social que estaba capturando la atención de los medios (la idea del joven héroe).

Respecto de la influencia concreta de Yeguada Latinoamericana y LasTesis en las formas de protestar en el país, no es posible dar con una respuesta cerrada, pues al revisar la historia del arte chileno en este ámbito, es posible encontrar conexiones con artistas que previamente influyeron, como por ejemplo ocurre en el caso de Eltit y Lemebel, para quienes el cuerpo es un terreno para la reflexión política (Freire, 2016) tratándose en este caso, de una ampliación de las formas de protestar, amparadas en las redes sociales a la hora de convocar, siendo la confianza personal el único filtro a la hora de sumar nuevos/as participantes en cada intervención pública, un detalle importante sobre todo en lo que respecta a las primeras intervenciones de LasTesis.

Desde estas bases, y, considerando los artivismos feministas, se vuelve necesario hacer una revisión de la cotidianeidad y a la vez, una revisión más profunda respecto de la(s) historia(s) inscritas como tal en el arte contemporáneo y la cultura visual en Chile, así como también se vuelve evidente cuestionar las historias e inscripciones que ya están ingresadas. Para ello se hace imprescindible leer el entorno y su contexto e inscribir desde allí nuevos cruces, instalar otras categorías de análisis, y, en definitiva, ampliar las miradas que permitan 
abrir fisuras y tirar de hilo, para remover las bases sobre las que están escritas. De lo contrario, repetiremos una y otra vez las formas de hacer y concebir la(s) historia(s) del arte. Desde esta línea, los feminismos tienen mucho que aportar al campo de los estudios visuales y de la historia del arte contemporáneo en Chile, pese a la molestia y zancadillas de algunos. Sin duda, las batallas por las inscripciones seguirán ocurriendo, desde diferentes lugares y desde distintos frentes. Ahí estaremos. 


\section{Referencias}

Alcázar, J., Fuentes, F. (2005). Performance y arte de acción en América Latina. México: CITRU, Ex Teresa y Ediciones sin nombre.

Alcoff, L. \& Potter, E. (1993). Feminist Epistemologies. New York, London: Routledge.

Anderson, B. \& Zinsser, J. (1991) Historia de las mujeres: una historia propia. Barcelona: Editorial Crítica.

Aponte, E. (1994). Nuestra invisibilidad en la historiografía nacional. Revista Frónesis, 1(2), pp.139-161.

Bauman, Z. (2004). Modernidad Líquida. Argentina: Fondo de Cultura Económica.

- (2004). Arte, ¿Líquido? Madrid: Sequitur.

Castillo, A. (2018). De la revuelta feminista, la historia y Julieta Kirkwood. En, F. Zerán (ed.), Mayo Feminista. La rebelión contra el patriarcado (pp. 35-48). Santiago de Chile: LOM.

Cruz, L. (enero-junio 2010). La Historia en clave feminista. Revista Venezolana de Estudios de la Mujer, 15(34), pp. 27-42.

Deleuze, G. \& Guattari, F. (1997). Mil Mesetas. Capitalismo y esquizofrenia. Valencia: Pre-Textos.

Devaud, A. (Enero-febrero 2020). La fuerza de las mujeres en la rebelión chilena. El fin del Feminismo. Le Monde Diplomatique, XX(214), p. 5.

Eco, U. (2007). Perspectivas de una semiótica de las artes visuales. Criterios, 25-28, pp. 221-233.

Flórez, J. (2015). Lecturas emergentes: Subjetividad, poder y deseo en los movimientos sociales. Bogotá: Editorial Pontificia Universidad Javeriana.

Foucault, M. (1979). La microfísica del poder. Madrid: La Piqueta.

Klinkenberg, J. M. (2006). Manual de semiótica general. Bogotá: Universidad de Bogotá Jorge Tadeo Lozano.

Lasalle, J. (2019). Ciberleviatán. El colapso de la democracia liberal frente a la revolución digital. Barcelona: ARPA.

Lugones, M. (Julio- Diciembre 2008). Colonialidad y género. Tabula Rasa, pp. 93-101.

Maffia, D. (2004). Contra las dicotomías: feminismo y epistemología crítica. Instituto Interdisciplinario de Estudios de Género. Recuperado de: http://dianamaffia.com.ar/archivos/Contra-lasdicotom\%C3\%ADas.-Feminismo-y-epistemolog\%C3\%ADa-cr\%C3\%ADtica.pdf ultimo acceso: 0705-2020.

Mellado, J. \& Richard, N. (eds.). (1983). Cuadernos de/para el análisis, 1, diciembre. Santiago de Chile.

Morales, L. (1998). Conversaciones con Diamela Eltit. Chile: Ed. Cuarto Propio.

Peirce, C. S. (1998). El hombre un signo. Barcelona: Editorial Crítica.

Richard, N. (2008). Feminismo, Género y Diferencia(s). Santiago de Chile: Palinodia.

- (coord.). (1987). Arte en Chile desde 1973. Escena de Avanzada y sociedad. Santiago de Chile: Contribuciones Programa FLACSO Chile, № 45.

- (2007). Fracturas de la memoria. Arte y pensamiento crítico. Buenos Aires: Siglo veintiuno.

- (2000). Políticas y estéticas de la memoria. Santiago de Chile: Editorial Cuarto Propio.

- (1998). Residuos y metáforas, Ensayos de crítica cultural sobre el Chile de la transición. Santiago de Chile: Cuarto Propio.

- (1994). La insubordinación de los signos: cambio político, transformaciones culturales y poéticas de la crisis. Santiago de Chile: Cuarto Propio.

- (1993). Masculino / Femenino, prácticas de la diferencia y cultura democrática. Santiago de Chile: Ed. Francisco Zegers.

- (1989). La estratificación de los márgenes. Santiago de Chile: Ed. Francisco Zegers.

- (2008). Márgenes e instituciones; arte en Chile desde 1973. Santiago de Chile: Metales Pesados.

- (2001). Ensayos de crítica cultural sobre el Chile de la transición. Chile: Editorial Cuarto Propio.

Richard, N., Oyarzún, P. Y Zaldívar C. (2005). Arte y Política de factorías. Santiago de Chile: Ediciones Universidad Arcis, Universidad de Chile y Consejo Nacional de las Artes.

Sánchez, C. (2005). Escenas del cuerpo escindido: ensayos cruzados de filosofía, literatura y arte. Chile: Universidad Arcis-Editorial Cuarto Propio. 
Trebisacce, C. (2016). Una historia crítica del concepto de experiencia de la epistemología feminista. Revista Cinta de Moebio, 57.

Valdés, A. (2006). Memorias Visuales, Arte Contemporáneo en Chile. Chile: Metales Pesados.

- (1996). Composición de lugar. Escritos sobre cultura. Chile: Editorial Universitaria.

Varela, N. (2019). Feminismo 4.0 La Cuarta Ola. Barcelona: Ediciones B.

Zerán, F. (ed.). (2018). Mayo Feminista. La rebelión contra el patriarcado. Santiago de Chile: LOM.

\section{Linkografía}

AAVV. (2018). Encuentro Plurinacional de Mujeres que Luchan. Coordinadora 8M. Recuperado de: https://www.londres38.cl/1934/articles-101321_recurso_1.pdf último acceso: 10-12-19.

Cabnal, L. (Septiembre de 2015). Feminista Comunitaria. SUDS Internacionalisme Solidaritat Feminismes. Recuperado de: https://suds.cat/experiencies/857-2/último acceso: 05-12-19.

Aladro-Vico, E., Jivkova-Semova, D., Bailey, O. (2018). Artivismo: Un nuevo lenguaje educativo para la acción social transformadora. Comunicar, Revista científica de Comunicación y Educación. DOI: https://doi.org/10.3916/C57-2018-01 Recuperado de: https://www.redalyc.org/jatsRepo/158/15856696001/html/index.html\#redalyc_15856696001_ ref27 último acceso: 27-12-2019.

Arditi, B. (2013). Las insurgencias no tienen un plan-ellas son el plan: performativos políticos y mediadores evanescentes. Hemispheric Institute E-misférica 10.2. Recuperado de: http://hemi.nyu.edu/hemi/es/e-misferica-102/arditi último acceso: 21-11-2019.

Contardo, Ó. (2018). El corazón rabioso del hombre loca. Gatopardo. Recuperado de: https://gatopardo.com/reportajes/escritor-pedro-lemebel/ último acceso: 22-11-2019.

Expósito, M. (2013). La potencia de la cooperación. Diez tesis sobre el arte politizado en la nueva onda global de movimientos. Barcelona: MACBA. Recuperado de: https://bit.ly/2rAHSRU último acceso: 27-12-2019.

Fernández, F. (Junio 2018). Nuestro mayo feminista: ¡La Revolución será feminista (anticapitalista, anticolonialista) o no será! Iberoamérica Social. Recuperado de: https://iberoamericasocial.com/wp-content/uploads/2018/06/Fern\%C3\%A1ndez-F.-2018.NUESTRO-MAYO-FEMINIST.-La-Revoluci\%C3\%B3n-ser\%C3\%A1-feminista-anticapitalistaanticolonialista-o-no-ser\%C3\%A1..pdf último acceso: 08-12-2019.

Flores, N. (29-10-2019). Manifestantes decapitaron busto de histórico militar y pusieron su cabeza en manos de Caupolicán. Página 7. Recuperado de: https://www.pagina7.cl/notas/actualidad/2019/10/29/manifestantes-decapitaron-busto-dehistorico-militar-y-pusieron-su-cabeza-en-manos-de-caupolican.shtml último acceso: 21-11-2019.

Freire, M. (2020). LasTesis. La calle (y el cuerpo) en disputa. Revista de Arte Contemporáneo Artishock. En: https://artishockrevista.com/2020/01/07/las-tesis/ último acceso: 17-01-2020.

- (2016). La insurrección del cuerpo en dictadura. La influencia de Diamela Eltit y Pedro Lemebel, Revista Historia Autónoma N 8, Universidad Autónoma de Madrid, España. e-ISSN: 2254-8726. Pp. 133-147. DOI: http://dx.doi.org/10.15366/rha2016 último acceso: 05-05-2020

- (2015). Territorios políticos, cuerpos politizados. Acerca del género en el arte de acción. Chile: 19701992. Tesis para optar al grado de Doctora en Historia y Teoría del Arte de la Universidad Autónoma de Madrid, España, dirigida por Dra. Patricia Mayayo Bost. Recuperado de: https://repositorio.uam.es/handle/10486/664025 último acceso: 19-01-2020.

Herner, A. (2009). Territorio, desterritorialización y reterritorialización: un abordaje teórico desde la perspectiva de Deleuze y Guattari. Revista Huellas no 13, pp. 160-171. Recuperado de: http://www.biblioteca.unlpam.edu.ar/pubpdf/huellas/n13a06herner.pdf último acceso: 19-012020.

Hanisch, C. (1969). The personal is political. Carol Hanisch, web oficial. Recuperado de: http://www.carolhanisch.org/CHwritings/PIP.html último acceso: 19-01-2020 
Huenchumil, P.; Mundaca, C. (08-11-2019). Derribar símbolos coloniales: Un nuevo acto político que se suma en las protestas en Chile. Interferencia. Recuperado de: https://interferencia.cl/articulos/derribar-simbolos-coloniales-un-nuevo-acto-politico-que-sesuma-en-las-protestas-en-chile?fbclid=IwAR2xOPWFjfZuR2oNYQIvcMp8pxR_20gAdEi2D0z77gGJx4v25a1AlXGUBI último acceso: 21-11-2019.

Linett, C., Concha, J., Remmele, L. (2018). Banda de Guerra - Yeguada Latinoamericana [manifiesto]. Vitrina Dystópica. Recuperado de: https://dystopica.org/2018/02/07/yeguada-latinoamericanabanda-de-guerra-manifiesto/ Recuperado: 19-01-2020

Lugones, M. (julio-diciembre 2008). Colonialidad y género. Tabula Rasa. Recuperado de: http://www.revistatabularasa.org/numero-9/05lugones.pdf último acceso: 21-11-2019.

Maffia, D. (2004). Contra las dicotomías: feminismo y epistemología crítica. Instituto Interdisciplinario de Estudios de Género. Recuperado de: http://dianamaffia.com.ar/archivos/Contra-lasdicotom\%C3\%ADas.-Feminismo-y-epistemolog\%C3\%ADa-cr\%C3\%ADtica.pdf ultimo acceso: 0705-2020.

Museo de la Dignidad. (2019). https://www.youtube.com/watch?v=bF2pAgnrq28 último acceso: 17-012020

Ortiz, J. (14-11-2017). Acoso y abuso sexual en universidades: 228 denuncias fueron recepcionadas en 2016. Publimetro. Recuperado de: https://www.publimetro.cl/cl/noticias/2017/11/14/acosoabuso-sexual-universidades-228-casos-fueron-recepcionados-2016.html Último acceso: 10-122019.

Portilla, C. (27-10-2019). Las imágenes que dejó la multitudinaria marcha en Viña del Mar y Valparaíso. La Tercera. Recuperado de: https://www.latercera.com/nacional/noticia/las-imagenes-dejo-lamultitudinaria-marcha-valparaiso/880019/ último acceso: 20-01-2020.

Ramírez, F. (04-03- 2019). Así fue el puntapié inicial del 8M: cortes en Alameda, Peñaflor y renombramiento a las estaciones de Metro. Publimetro. Recuperado de: https://www.publimetro.cl/cl/noticias/2019/03/04/previa-8m-dia-de-la-mujer-huelgafeminista.html último acceso: 10-12-2019.

Rodríguez, D. (28-11-2019). Ellas son las chilenas que crearon Un violador en tu camino. Verne, El País. Recuperado de: https://verne.elpais.com/verne/2019/11/28/mexico/1574902455_578060.html último acceso: 04-12-2019.

S/A. (09 - 03- 2019). La movilización más grande de la historia: Coordinadora 8M realiza balance de huelga feminista y cifra en 800 mil mujeres movilizadas. El Desconcierto. Recuperado de: https://www.eldesconcierto.cl/2019/03/09/la-movilizacion-mas-grande-de-la-historia-tienerostro-de-mujer-coordinadora-8m-realiza-balance-de-huelga-feminista-y-cifra-en-800-milmujeres-movilizadas-a-nivel-nacional/ último acceso: 18-11-2019.

S/A. (29-11-2019). Un violador en tu camino: Himno feminista de Lastesis es interpretado en todo Chile, América Latina y Europa. CNN Chile. Recuperado de: https://www.cnnchile.com/mundo/unviolador-en-tu-camino-lastesis-videos-mundo_20191129/ Último acceso: 13-12-2019.

S/A. (09-03-2019). La movilización más grande de la historia: Coordinadora 8M realiza balance de huelga feminista y cifra en 800 mil mujeres movilizadas. El Desconcierto. Recuperado de: https://www.eldesconcierto.cl/2019/03/09/la-movilizacion-mas-grande-de-la-historia-tienerostro-de-mujer-coordinadora-8m-realiza-balance-de-huelga-feminista-y-cifra-en-800-milmujeres-movilizadas-a-nivel-nacional/ último acceso: 13-12-2019.

S/A. (25-10-2019). Los históricos registros que dejó "La Marcha más grande de Chile". El Desconcierto. Recuperado de: https://www.eldesconcierto.cl/2019/10/25/los-historicos-registros-que-dejo-lamarcha-mas-grande-de-chile/ último acceso: 20-01-2020.

S/A. (08-12- 2018). Encuentro Plurinacional de Mujeres que Luchan: La convocatoria ha sido histórica. El Desconcierto. Recuperado de: https://www.eldesconcierto.cl/2018/12/08/encuentroplurinacional-de-mujeres-que-luchan-la-convocatoria-ha-sido-historica/ último acceso: 13-112019. 
S/A. (26-10- 2019). La marcha más grande de Chile: las cifras que la sitúan como la más masiva en décadas. Tele13radio. Recuperado de: https://www.t13.cl/noticia/nacional/marcha-mas-grandede-chile-masiva-26-10-2019 último acceso: 1-12-2019.

S/A. (04-03-2019). "Esta fue la intervención feminista que le cambió los nombres a las estaciones del Metro de Santiago", The Clinic. Recuperado de:https://www.theclinic.cl/2019/03/04/galeria-estafue-la-intervencion-feminista-que-le-cambio-los-nombres-a-las-estaciones-del-metro-desantiago/ último acceso: 13-12-2019.

Salinas, M. (15- 05- 2018). Sólo 7 de 60 universidades tenían protocolos activos contra el acoso a noviembre de 2017.El Dínamo. Recuperado de: https://www.eldinamo.cl/educacion/2018/05/15/solo-7-de-60-universidades-tenianprotocolos-activos-contra-el-acoso-a-noviembre-de-2017/

Segato, R. (2016). La guerra contra las mujeres. Madrid: Traficantes de sueños. Recuperado de: https://www.traficantes.net/sites/default/files/pdfs/map45_segato_web.pdf último acceso: 1901-2020.

Sepúlveda P. (13-05-2019). "A un año del Mayo Feminista", Qué Pasa. Recuperado de: https://www.latercera.com/que-pasa/noticia/mayo-feminista-en-chile/648290/ último acceso: 13-12-2019.

Salinas, M. (15- 05- 2018). Sólo 7 de 60 universidades tenían protocolos activos contra el acoso a noviembre de 2017.El Dínamo. Recuperado de: https://www.eldinamo.cl/educacion/2018/05/15/solo-7-de-60-universidades-tenianprotocolos-activos-contra-el-acoso-a-noviembre-de-2017/

Tabares, C. (2019). “Teorías críticas feministas. Transgresoras, creativas: una contribución a los desafíos de la teoría social en América Latina". NORUS. Vol. 7, no 11 . Jan/Jul. Pp. 85-112. Recuperado de: https://www.researchgate.net/publication/335585718_TEORIAS_CRITICAS_FEMINISTAS_TRANS GRESORAS_CREATIVAS_UNA_CONTRIBUCION_A_LOS_DESAFIOS_DE_LA_TEORIA_SOCIAL_EN_AME RICA_LATINA último acceso: 07-05-2020.

TheClínic, GALERÍA. (04-03-2019). Esta fue la intervención feminista que le cambió los nombres a las estaciones del Metro de Santiago. Recuperado de: https://www.theclinic.cl/2019/03/04/galeriaesta-fue-la-intervencion-feminista-que-le-cambio-los-nombres-a-las-estaciones-del-metro-desantiago/ último acceso: 18-11-2019.

Valencia S. (08-06-2018). Hermanadas en la turba, hermanadas en la revuelta: Yeguada Latinoamericana. Artishock. Recuperado de: http://artishockrevista.com/2018/06/08/hermanadas-en-la-turbahermanadas-en-la-revuelta-yeguada-latinoamericana/último acceso: 18-11-2019. 